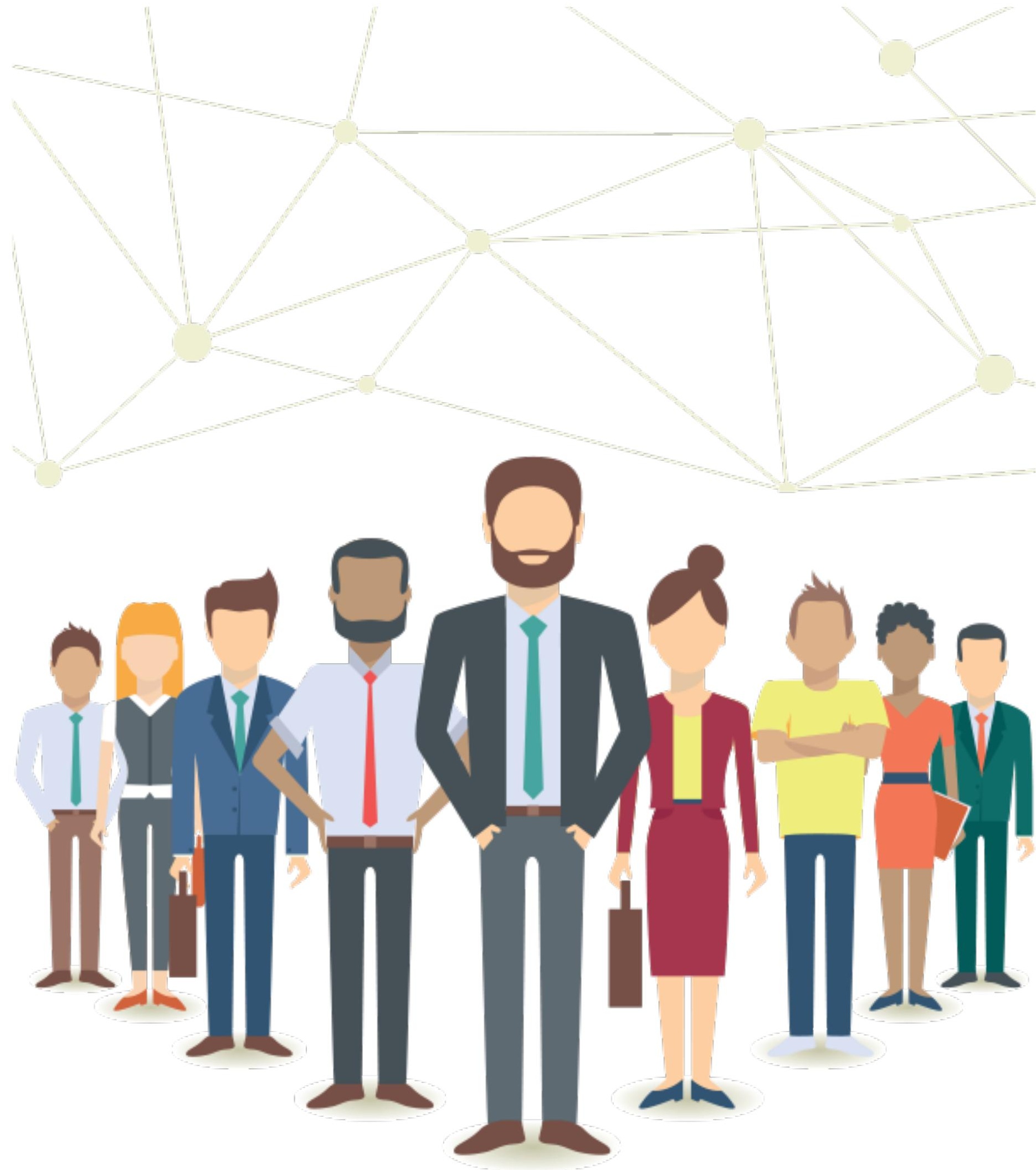




\section{COMPETÊNCIAS PROFISSIONAIS EM GESTÃO DA QUALIDADE: PERCEPCCÃO=DE-DISCENTES DE UMA INSTITUIÇÃO DE ENSINO SUPERIOR PARTICULAR SITUADA EM BELO HORIZONTE}

PROFESSIONAL SKILLS IN QUALITY MANAGEMENT:
PERSPECTIVE OF STUDENTS FROM AIPRIVATE=:=
UNIVERSITY LOCATED IN BELO HORIZONTE

COMPETENCIAS PROFESIONALES EN GESTIÓN DE LA CALIDAD: PERCEPCIÓN DE ESTUDIANTES DE UNA INSTITUCIÓN DE EDUCACIÓN SUPERIOR PARTICULAR SITUADA EN BELO HORIZONTE

\section{Valéria Rezende Freitas Barros* Marlene Catarina de Oliveira Lopes Melo**}

*Mestre em Administração pela Faculdade Novos Horizontes. Belo Horizonte, Minas Gerais, Brasil. E-mail: valeria.barros@ unihorizontes.br

** Doutora em Ciências das Organizações pela Université Paris IX - Dauphine, França. Diretora Geral da Faculdade Novos Horizontes e Diretora de Pós-Graduação, Ensino e Extensão. Coordenadora do Mestrado em Administração da Faculdade Novos Horizontes. Coordenadora do Núcleo de Relações de Trabalho e Tecnologia de Gestão (Nurteg). Belo Horizonte, Minas Gerais, Brasil. E-mail: lenemelo@unihorizontes.br

Recebido para publicação em: 1.9.2016

Aprovado em: 4.1.2017

\section{Resumo}

Este artigo analisa as contribuições do curso de Graduação Tecnológica em Gestão da Qualidade de uma instituição de ensino superior particular de Belo Horizonte na formação de competências profissionais de discentes, na percepção dos próprios sujeitos. Verificou-se que o curso pesquisado, de modo geral, tem sido efetivo em desenvolver competências profissionais nos alunos. Constatou-se, ainda, que os respondentes consideraram desejável que todas as competências prescritas na Resolução do Conselho Nacional de Educação/Conselho Pleno (CNE/CP) n. 3 sejam efetivamente desenvolvidas pelo curso.

Palavras-chave: Competências profissionais. Graduação tecnológica. Gestão da Qualidade. Discentes.

\section{Abstract}

This article analyzes contributions from the Technological graduation course in Quality Management from a private university in Belo Horizonte in developing professional skills in students, in the perspective of the students themselves. It was found that the researched course, in general, has been effective in developing professional skills in its students. It was also found that the 
respondents considered to be desirable that all competences provided in the National Education Council (CNE/CP) Resolution no3 would be effectively developed by the course.

Keywords: Professional Skills. Technological Graduation. Quality Management. Students.

\section{Resumen}

Este artículo analiza las contribuciones de la carrera de Graduación Tecnológica en Gestión de la Calidad de una institución de educación superior particular de Belo Horizonte en la formación de competencias profesionales de estudiantes, desde la percepción de los propios sujetos. Se ha verificado que la carrera investigada, de modo general, ha sido efectiva al desarrollar competencias profesionales en los alumnos. Se ha constatado, incluso, que los encuestados consideraron deseable que todas las competencias prescritas en la Resolución del Consejo Nacional de Educación/Consejo Pleno (CNE/ CP) n. 3 sean efectivamente desarrolladas por la carrera.

Palabras clave: Competencias profesionales. Graduación tecnológica. Gestión de la Calidad. Estudiantes.

\section{Introdução}

A partir da década de 1980, nos países capitalistas avançados, ocorreram mudanças no processo produtivo, no cenário competitivo e nas tecnologias, o que despertou um crescente interesse tanto da área gerencial quanto da área acadêmica pelas competências profissionais (BITENCOURT, 2002; PAIVA et al., 2011).

Assim, as organizações passaram a procurar por profissionais flexíveis, bem formados e informados, multifuncionais e polivalentes, com habilidades distintas, capazes de tomar decisões rápidas e efetivas, que possuam conhecimentos além daqueles formalizados e que se qualifiquem continuamente (BITENCOURT, 2002; PAIVA et al., 2011).

Diante dessas novas competências exigidas do trabalhador pelo mercado de trabalho, surgiu a necessidade de se formar profissionais capazes de atendê-las (BITENCOURT, 2002). Dessa forma, as competências profissionais passaram a ser abordadas no contexto da educação, aparecendo tanto na educação técnica quanto na profissional (PAIVA et al., 2011; STEFFEN, 1999). 
Segundo Ramos (2002), as instituições de ensino superior devem formar pessoas competentes, para que, ao adentrarem o mercado de trabalho após o término dos cursos, não enfrentem muitas dificuldades, as quais, geralmente, estão relacionadas à discrepância entre a preparação que tiveram nos cursos e a realidade profissional.

Um profissional competente deve ser capaz de agir responsavelmente, ser reconhecido e, ainda, "mobilizar, integrar, transferir conhecimentos, recursos, habilidades, que agreguem valor econômico à organização e valor social ao indivíduo" (FLEURY; FLEURY, 2001, p. 4). Ou seja, as competências profissionais explicitadas por esses autores englobam alguns saberes, quais sejam: agir, mobilizar, comunicar, aprender, comprometer-se, assumir responsabilidades e ter visão estratégica.

Quais as contribuições que um curso de nível tecnológico traz para a formação de competências profissionais de discentes?
Tendo em vista as novas competências requeridas dos profissionais no mercado de trabalho, principalmente aquelas exigidas pela expansão tecnológica (RAMOS, 2002), o Estado criou regulamentações visando que as áreas educacionais se adequassem a essas mudanças, formando indivíduos capazes de atender às exigências organizacionais (BRANDÃO, 2006).

Para a educação tecnológica, o Estado, por meio da Resolução CNE/CP n. 3, de 18 de dezembro de 2002, propôs diretrizes curriculares para os cursos de nível tecnológico. De acordo com essa resolução,

\section{a educação profissional de nível tecnológico, integrada às di- ferentes formas de educação, ao trabalho, à ciência e à tec- nologia, objetiva garantir aos cidadãos o direito à aquisição de competências profissionais que os tornem aptos para a inserção em setores profissionais nos quais haja utilização de tecnologias (CONSELHO NACIONAL DE EDUCAÇÃO, 2002, p. 1).}

Diante desse contexto, a pergunta norteadora desta pesquisa foi: Quais as contribuições que um curso de nível tecnológico traz para a formação de competências profissionais de discentes? Para respondê-la, foi traçado o seguinte objetivo: analisar as contribuições do curso de Graduação Tecnológica em Gestão da Qualidade de uma Instituição de Ensino Superior (IES) particular, situada em Belo Horizonte, na formação de competências profissionais de discentes, na percepção dos próprios sujeitos.

A relevância deste estudo deve-se ao fato de que a temática Competência Profissional está ganhando espaço no âmbito das organizações e no âmbito acadêmico, tendo em vista o novo perfil profissional exigido no mercado de trabalho (BITENCOURT, 2002; PAIVA et. al., 2011).

Este artigo está estruturado em seis seções. Após esta introdução, aborda-se o referencial teórico e, na terceira seção, descreve-se a metodologia utilizada nesta pesquisa. Na quarta seção, apresenta-se a análise dos resultados e, na sequência, as considerações finais, seguida pelas referências. 


\section{Referencial teórico sobre competência profissional}

Pode-se dizer que a competência é um tema que vem sendo discutido em diferentes áreas do conhecimento e possui diferentes enfoques, os quais ampliam e enriquecem modelos propostos por diversos autores (DUTRA; HIPÓLITO; SILVA, 2000; PAIVA, et. al. 2013; STEFFEN, 1999).

Acredita-se que a primeira vez que o termo competência surgiu foi na língua francesa, no século 15. O termo do latim competentia, proporção, justa relação, significa aptidão, idoneidade; retratava a faculdade que algumas pessoas possuíam para apreciar ou resolver um assunto, "designando a legitimidade e a autoridade das instituições para tratar determinados problemas" (DIAS, 2010, p. 74). A partir dos anos 70, devido ao amplo debate sobre as competências profissionais no âmbito das táticas gerenciais organizacionais (BARBOSA, 2003), o termo "surge associado à qualificação profissional, vinculando-se ao posto de trabalho e associando-se ao coletivo, à organização" (DIAS, 2010, p. 74).

Devido às complexidades presentes no trabalho e aos conhecimentos e habilidades necessários para desenvolvê-lo, conceituar competência profissional não é uma tarefa fácil (CHEETHAM; CHIVERS, 1996).

Segundo Brandão (2006), competência tornou-se uma forma de quantificar a performance e os resultados das pessoas no trabalho. Refere-se a uma união de qualificações ou características exaltáveis, que possibilitam às pessoas terem desempenho superior em algum trabalho ou situação (DUTRA; HIPÓLITO; SILVA, 2000).

Seguindo a mesma linha de raciocínio de Dutra, Hipólito e Silva (2000), para Zarifian (2001), a competência profissional refere-se à capacidade dos indivíduos de superarem expectativas, de se sobressaírem em ambientes de mudanças constantes, de serem responsáveis pelo próprio desempenho e, ainda, de terem reconhecimento de seus desempenhos por parte de terceiros que estão à sua volta.

Segundo Ceitil (2010), a competência profissional consiste nos comportamentos das pessoas, tendo em vista que eles podem ser mensurados, analisados e avaliados de acordo com a capacidade do indivíduo de desenvolver seu trabalho. Em outras palavras, Ceitil (2010) caracteriza a competência com uma forma de agir específica (outputs) que deve ser reconhecida por terceiros, e engloba, também, as características intrínsecas das pessoas (inputs), sendo estas específicas ou não.
A competência profissional refere-se à capacidade dos indivíduos de superarem expectativas 
Baseado no modelo de Le Boterf (2003), Fleury e Fleury (2004) desenvolveram um modelo de competência profissional que abrange sete saberes, conforme discriminado no Quadro 1.

\section{Quadro 1 - Competências profissionais segundo Fleury e Fleury (2004)}

\begin{tabular}{|c|c|}
\hline Competências & Significados \\
\hline Saber agir & $\begin{array}{c}\text { Saber o que e o porquê fazer. Saber julgar, } \\
\text { escolher e decidir. }\end{array}$ \\
\hline Saber mobilizar & $\begin{array}{c}\text { Saber mobilizar recursos de pessoas, financeiros, } \\
\text { materiais, criando sinergia entre eles. }\end{array}$ \\
\hline Saber comunicar & $\begin{array}{c}\text { Compreender, processar, transmitir informações e } \\
\text { conhecimentos, assegurando o entendimento da } \\
\text { mensagem pelos outros. }\end{array}$ \\
\hline Saber aprender & $\begin{array}{c}\text { Trabalhar o conhecimento e a experiência. Rever } \\
\text { modelos mentais. Saber desenvolver-se e propiciar o } \\
\text { desenvolvimento dos outros. }\end{array}$ \\
\hline $\begin{array}{c}\text { Saber } \\
\text { comprometer-se }\end{array}$ & $\begin{array}{c}\text { Saber engajar-se e comprometer-se com os } \\
\text { objetivos da organização. }\end{array}$ \\
\hline $\begin{array}{c}\text { Saber assumir } \\
\text { responsabilidades }\end{array}$ & $\begin{array}{c}\text { Ser responsável, assumir os riscos e as } \\
\text { consequências de suas ações e ser, por isso, } \\
\text { reconhecido. }\end{array}$ \\
\hline $\begin{array}{c}\text { Ter visão } \\
\text { estratégica }\end{array}$ & $\begin{array}{c}\text { Conhecer e entender o negócio da organização, } \\
\text { seu ambiente, identificando oportunidades e } \\
\text { alternativas. }\end{array}$ \\
\hline
\end{tabular}

Fonte: Fleury e Fleury (2004, p. 31).

Uma vez que as competências profissionais estão atreladas ao "saber agir, mobilizar recursos, integrar saberes múltiplos e complexos, saber aprender, saber se engajar, assumir responsabilidades e ter visão estratégica", elas "devem agregar valor econômico para a organização e valor social para o indivíduo" (FLEURY; FLEURY, 2004, p. 31).

Para Paiva e Melo (2008), as competências consistem em um modo de agir pessoal, reconhecido individualmente, coletivamente, economicamente e socialmente, referindo-se à união de conhecimentos e saberes de natureza diferenciada.

Indivíduo competente refere-se a um "sujeito autônomo em relação ao uso do saber". Aquele que tem a possibilidade de ativar conhecimentos, capacidades e estratégias (recursos) em inúmeras situações, principalmente, em 
situações problemáticas. Em outras palavras, refere-se à pessoa capaz de recorrer a seus conhecimentos para realizar o que se deseja. Assim, uma pessoa competente é aquela que "num determinado domínio, enfrenta eficazmente uma situação inesperada, mobilizando e conjugando saberes, saberes-fazer e técnicas" (DIAS, 2010, p. 75).

No âmbito educacional, devido ao cenário de mudanças, competitividade e novas exigências, as instituições de ensino enfrentam o desafio de formar indivíduos com competências essenciais para enfrentar sua prática profissional (FLEURY; VASCONCELLOS, 2009; SILVA, 2008).

Salienta-se que a escola, assim como várias outras instituições presentes na sociedade, é definida e balizada pelas necessidades e demandas do capitalismo. Assim, os projetos pedagógicos (KUENZER; GRABOWSK, 2016), a identidade do professor e, consequentemente, das pessoas por ele influenciadas no processo de educar (HYPOLITO, 2010) e as competências desenvolvidas pelos cursos (relação entre teoria e prática, flexibilidade) (KUENZER; GRABOWSK, 2016) são pautadas nas demandas das forças produtivas (FERRETTI, 2014; HIRATA, 2016; HYPOLITO, 2010; KUENZER, 2015; KUENZER; GRABOWSK, 2016).

Ainda nesse sentido, devido a essa formação de identidade do profissional, tem-se a instabilidade e precarização do trabalho, o aumento de certificações em detrimento de uma educação de qualidade e emancipatória e a carência de sujeitos capazes de transformar a realidade (HIRATA, 2016; KUENZER, 2015), a consciência política (HYPOLITO, 2010) e de avaliar as influências da sua atuação nos âmbitos políticos, econômicos, sociais e culturais (FERRETTI, 2014).

Assim, a competência pode se referir à capacidade das pessoas de desenvolver, de forma satisfatória, sua vida profissional. A partir dessa capacidade, o indivíduo poderá ter melhores possibilidades de emprego, tendo em vista a relação existente entre o saber e o mercado de trabalho, ou seja, entre qualificação e emprego (SCHAEPER, 2009).

De acordo com Zabala e Arnau (2010) as competências, na Educação, englobam o saber, conhecimento que o indivíduo possui; o saber fazer, que consiste nas habilidades que possui; e o saber ser, que se refere à atitude. Referem-se, também, às características identificáveis e observáveis, aos conhecimentos, às atitudes, às aptidões, às habilidades, aos valores, à motivação e aos comportamentos mensuráveis apresentados por estudantes do ensino superior (GIL-ESTALLO et al., 2010).

Ressalta-se que as competências no mundo do trabalho e no âmbito acadêmico têm assumido inúmeros significados, podendo enfatizar tanto carac- 
terísticas pessoais quanto exigências dos cargos ou postos de trabalho, bem como processos e resultados (PAIVA et al., 2013).

A aquisição e renovação das competências profissionais podem se dar por meio da educação profissional continuada

\section{Diretrizes curriculares nacionais para os cursos superiores de Tecnologia}

Posteriormente à aprovação da Lei n. 9.394/96, por meio do Decreto n. 2.208/97, ocorreram algumas reformas na educação profissional brasileira, especialmente a separação estrutural entre o ensino médio e o ensino técnico.

Em seguida a essa separação estrutural, sobrevieram também mudanças na estrutura curricular, introduzindo as competências, as quais passaram a ser a referência primordial na estrutura curricular da educação profissional (RAMOS, 2002).

Um currículo baseado em competência parte da análise do processo de trabalho, da qual se constrói uma matriz referencial a ser transportada pedagogicamente para uma organização modular, adotando-se uma abordagem metodológica baseada em projetos ou resolução de problemas (RAMOS, 2002, p. 404).

A partir desses princípios, a Secretaria de Educação Média e Tecnológica (SEMTEC/ MEC) realizou estudos e os enviou à Câmara de Educação Básica do Conselho Nacional de Educação, os quais deram origem às Diretrizes Curriculares Nacionais (DCNs) e aos Referenciais Curriculares Nacionais (RCNs) da Educação Profissional (RAMOS, 2002).

As instituições de ensino passaram a ter maior liberdade na elaboração das grades curriculares, flexibilizando a fixação de conteúdo, considerando as cargas horárias predeterminadas e reduzindo a longa duração dos cursos. Passaram, também, a estimular uma formação geral, a firmar uma maior articulação entre teoria e prática e a encorajar os alunos a buscarem outras habilidades, competências e conhecimentos, além dos adquiridos e estimulados no ambiente acadêmico (FRAUCHES, 2008).

Assim, a aquisição e renovação das competências profissionais podem se dar por meio da educação profissional continuada ou por meio de experiências profissionais diversificadas (RAMOS, 2002).

A resolução CNE/CP n. 3, de 18 de dezembro de 2002, institui as Diretrizes Curriculares Nacionais Gerais para a organização e o funcionamento dos cursos superiores de tecnologia. No seu artigo 1ํㅡ, consta que a educação profissional de nível tecnológico, integrada às distintas formas de educação, 
trabalho, ciência e tecnologia, visa assegurar aos cidadãos o direito de adquirir competências profissionais. Essas competências devem tornar os cidadãos capazes de se inserirem nos setores profissionais em que haja uso de tecnologias (CONSELHO NACIONAL DE EDUCAÇÃO, 2002).

No artigo $2^{\text {o }}$ dessa resolução, no decorrer de seus parágrafos de I a VII, são apresentadas as competências que o curso de educação profissional de nível tecnológico deve desenvolver, a saber:

I - incentivar o desenvolvimento da capacidade empreendedora e da compreensão do processo tecnológico, em suas causas e efeitos;

II - incentivar a produção e a inovação científico-tecnológica, e suas respectivas aplicações no mundo do trabalho;

III - desenvolver competências profissionais tecnológicas, gerais e específicas, para a gestão de processos e a produção de bens e serviços;

IV - propiciar a compreensão e a avaliação dos impactos sociais, econômicos e ambientais resultantes da produção, gestão e incorporação de novas tecnologias;

$\mathrm{V}$ - promover a capacidade de continuar aprendendo e de acompanhar as mudanças nas condições de trabalho, bem como propiciar o prosseguimento de estudos em cursos de Pós-Graduação;

VI - adotar a flexibilidade, a interdisciplinaridade, a contextualização e a atualização permanente dos cursos e seus currículos;

VII - garantir a identidade do perfil profissional de conclusão de curso e da respectiva organização curricular (CONSELHO NACIONAL DE EDUCAÇÃO, 2002, p. 1).

De acordo com o parágrafo 6⿳0 da resolução CNE/CP n. 3, a organização curricular dos cursos superiores de nível tecnológico deverá ser capaz de desenvolver nos alunos competências profissionais de distintas áreas e, principalmente, competências profissionais tecnológicas gerais e específicas, incluindo os fundamentos científicos e humanísticos fundamentais para o desempenho profissional do concluinte de nível tecnológico.

Competência profissional refere-se à capacidade individual de "mobilizar, articular e colocar em ação conhecimentos, habilidades, atitudes e valores necessários para o desempenho eficiente e eficaz de atividades requeridas pela natureza do trabalho e pelo desenvolvimento tecnológico" (CONSELHO NACIONAL DE EDUCAÇÃO, 2002, p. 3). Nesse sentido, um sujeito competente é aquele capaz de utilizar seus conhecimentos, habilidades e valores para atender às demandas do trabalho e do desenvolvimento tecnológico, buscando ter um desempenho eficiente e eficaz. 
Diante das considerações acerca das competências realizadas nesta seção e, principalmente, tendo em vista as competências que um curso de graduação tecnológica deve desenvolver nos alunos, traçou-se um percurso metodológico visando identificar as particularidades de um Curso Tecnológico em Gestão da Qualidade, exposto a seguir.

\section{Metodologia}

Trata-se de uma pesquisa de abordagem quantitativa que, por sua vez, busca quantificar características do fenômeno em estudo (VERGARA, 2009). Nesta pesquisa, buscou-se quantificar os níveis de satisfação e insatisfação dos alunos quanto às reais e ideais contribuições do curso no desenvolvimento de competências profissionais.

Quanto aos fins, esta pesquisa se caracteriza como descritiva, a qual busca expor as especificidades de determinada população ou fenômeno (GODOY, 1995; VERGARA, 2009). Neste caso, buscou-se descrever as contribuições do curso de Graduação Tecnológica em Gestão da Qualidade na formação de competências profissionais de seus discentes.

Quanto aos meios, esta pesquisa se caracteriza como estudo de caso. Nesse tipo de pesquisa, a investigação está centrada em um caso específico (SEVERINO, 2007). Assim, o caso estudado foi de discentes de um curso de Graduação Tecnológica em Gestão da Qualidade de uma IES privada localizada na cidade de Belo Horizonte. A unidade de análise foram 27 discentes matriculados no $3^{\circ}$ ou $4^{\circ}$ período do referido curso. Ressalta-se que essa IES está há mais de dez anos no ramo educacional e oferta vários cursos de graduação (bacharelado e tecnológica) e pós-graduação (lato sensu e stricto sensu).

A coleta de dados foi realizada por meio de um questionário, dividido em duas partes. Na primeira parte, buscou-se identificar dados demográficos dos discentes pesquisados; na segunda parte, as competências desenvolvidas (reais) e que deveriam ser desenvolvidas (ideais) nesses discentes, tendo por base as Diretrizes Curriculares Nacionais para o curso e o modelo de competência profissional apresentado por Fleury e Fleury (2004) na literatura. Nessa fase, os incisos da CNE/CP n. 3 (CONSELHO NACIONAL DE EDUCAÇÃO, 2002) foram subdivididos em afirmativas, as quais foram classificadas de acordo com as competências profissionais propostas por Fleury e Fleury (2004). Nesse sentido, os respondentes deveriam indicar seu nível de concordância em relação às afirmativas, considerando duas variáveis: as competências profissionais que deveriam ter sido desenvolvidas nos discentes (ideais) e aquelas que efetivamente foram desenvolvidas (reais). A escala de avaliação utilizada no questionário foi do tipo Likert, com cinco pontos, 
sendo assinalado 1 quando os respondentes estavam completamente insatisfeitos e assinalado 5 quando estavam completamente satisfeitos.

Foram distribuídos 37 questionários, dos quais se obteve 27 preenchidos completamente e 3 invalidados devido ao preenchimento incompleto. Os dados foram lançados em planilha do Excel e, posteriormente, foi realizada uma análise por meio de estatística descritiva dos dados.

\section{Apresentação e análise dos dados}

Primeiramente, foram apresentados os dados demográficos, acadêmicos e profissionais dos discentes que responderam o questionário. Em seguida, foram apresentados os dados referentes aos níveis reais de contribuição do curso de Graduação Tecnológica em Gestão da Qualidade no desenvolvimento de competências profissionais nos discentes. Em um terceiro momento, foram apresentados os dados referentes aos níveis desejáveis/ideais de contribuição do curso no desenvolvimento de competências profissionais nos discentes.

\subsection{Dados demográficos, acadêmicos e profissionais dos respondentes}

Os dados demográficos, acadêmicos e profissionais dos discentes respondentes desta pesquisa estão relacionados a sexo, faixa etária, estado civil, semestre em curso, experiência profissional, renda mensal e nível do cargo ocupado, conforme pode ser visualizado na Tabela 1, na página seguinte.

Foram apresentados os dados referentes aos níveis desejáveis/ideais de contribuição do curso no desenvolvimento de competências profissionais nos discentes 


\section{Tabela 1- Dados demográficos, acadêmicos e profissionais dos respondentes}

\begin{tabular}{|c|c|c|}
\hline \multicolumn{2}{|c|}{ Dados demográficos e funcionais dos respondentes } & Total \\
\hline \multirow{2}{*}{ Sexo } & Masculino & 17 \\
\hline & Feminino & 10 \\
\hline \multirow{6}{*}{ Faixa etária } & Menos de 20 anos & 3 \\
\hline & De 21 a 25 anos & 3 \\
\hline & De 26 a 30 anos & 10 \\
\hline & De 31 a 35 anos & 3 \\
\hline & De 36 a 40 anos & 5 \\
\hline & De 41 a 45 anos & 3 \\
\hline \multirow{3}{*}{ Estado civil } & Solteiro & 15 \\
\hline & Casado & 9 \\
\hline & Separado ou divorciado & 3 \\
\hline \multirow{2}{*}{ Semestre em curso } & 30 & 22 \\
\hline & $4 \underline{0}$ & 5 \\
\hline \multirow{6}{*}{$\begin{array}{l}\text { Experiência } \\
\text { profissional }\end{array}$} & Nenhuma experiência profissional & 1 \\
\hline & Menos de 2 anos & 3 \\
\hline & De 2 a 5 anos & 5 \\
\hline & De 6 a 10 anos & 6 \\
\hline & De 11 a 15 anos & 10 \\
\hline & De 16 a 20 anos & 2 \\
\hline \multirow{2}{*}{ Renda mensal } & Até R\$1.000,00 & 5 \\
\hline & De $R \$ 1.001,00$ a $R \$ 3.000,00$ & 22 \\
\hline \multirow{3}{*}{$\begin{array}{c}\text { Nível do cargo } \\
\text { ocupado }\end{array}$} & Operacional & 10 \\
\hline & Técnico & 14 \\
\hline & Gerencial & 3 \\
\hline
\end{tabular}

Fonte: Dados da pesquisa.

Quanto aos dados demográficos, a partir da Tabela 1, identificou-se que a maioria dos respondentes é homem e solteiro. Dez discentes respondentes possuem entre 26 e 30 anos, enquanto cinco estão na faixa etária entre 36 e 40 anos de idade. Quanto aos dados acadêmicos, verificou-se que a maioria dos discentes cursava o 3 o semestre da Graduação Tecnológica em Gestão da Qualidade. No que se refere aos dados profissionais dos discentes, constatou-se que dez deles possuem mais de 11 anos de experiência profissional e seis possuem entre 6 e 10 anos de experiência profissional. A maioria possui renda mensal entre $\mathrm{R} \$ 1.001,00$ e $\mathrm{R} \$ 3.000,00$ e mais da metade dos discentes pesquisados ocupa cargos de natureza técnica. 
Com base nos dados profissionais dos discentes, constatou-se que 23 respondentes já estavam inseridos no mercado de trabalho quando iniciaram a Graduação Tecnológica em Gestão da Qualidade na IES.

\subsection{Níveis efetivos (reais) da contribuição do curso no desenvolvimento de competências profissionais nos discentes}

Conforme já mencionado nesta pesquisa, na CNE/CP n. 3 são descritas as competências profissionais que os cursos de nível tecnológico devem desenvolver nos alunos. Considerando essas prescrições, na Tabela 2, foram descritas a média e o desvio padrão identificados a partir das respostas dos discentes pesquisados em relação ao nível de satisfação quanto à real contribuição do curso de Graduação Tecnológica em Gestão da Qualidade no desenvolvimento de suas competências profissionais.

\section{Tabela 2 - Nível de satisfação dos discentes em relação à real contribuição do curso no desenvolvimento de suas competências profissionais}

\begin{tabular}{c|c|c|c}
\hline $\mathbf{N}$ & Questão & Média & $\begin{array}{c}\text { Desvio } \\
\text { Padrão }\end{array}$ \\
\hline $\mathbf{1}$ & $\begin{array}{c}\text { Incentiva o desenvolvimento da } \\
\text { capacidade empreendedora nos alunos no } \\
\text { campo da Gestão da Qualidade }\end{array}$ & 3,41 & 0,89 \\
\hline $\mathbf{2}$ & $\begin{array}{c}\text { Incentiva a compreensão dos processos de } \\
\text { aferição da Qualidade }\end{array}$ & 3,52 & 0,85 \\
\hline $\mathbf{3}$ & $\begin{array}{c}\text { Promove a compreensão das causas que } \\
\text { justificam a implantação do processo da } \\
\mathbf{4}\end{array}$ & $\begin{array}{c}\text { Qualidade } \\
\text { decorrentes da implantação do processo } \\
\text { da Qualidade }\end{array}$ & 3,89 \\
\hline $\mathbf{5}$ & $\begin{array}{c}\text { Incentiva a produção científico- } \\
\text { tecnológica e suas respectivas aplicações } \\
\text { no campo da Gestão da Qualidade }\end{array}$ & 3,41 & 0,89 \\
\hline $\mathbf{6}$ & $\begin{array}{c}\text { Incentiva a inovação científico-tecnológica } \\
\text { e suas respectivas aplicações no campo da } \\
\text { Gestão da Qualidade }\end{array}$ & 3,33 & 0,89 \\
\hline $\mathbf{7}$ & $\begin{array}{c}\text { Desenvolve competências profissionais } \\
\text { tecnológicas gerais, para a gestão de } \\
\text { processos na área da Qualidade }\end{array}$ & 3,56 & 0,85 \\
\hline
\end{tabular}


(continuação)

\begin{tabular}{|c|c|c|c|}
\hline 8 & $\begin{array}{l}\text { Desenvolve competências profissionais } \\
\text { tecnológicas gerais para a produção de } \\
\text { bens e serviços no campo da Qualidade }\end{array}$ & 3,59 & 0,89 \\
\hline 9 & $\begin{array}{c}\text { Desenvolve competências profissionais } \\
\text { tecnológicas específicas para a gestão de } \\
\text { processos na área da Qualidade }\end{array}$ & 3,44 & 0,58 \\
\hline 10 & $\begin{array}{c}\text { Desenvolve competências profissionais } \\
\text { tecnológicas específicas para a produção } \\
\text { de bens e serviços no campo da } \\
\text { Qualidade }\end{array}$ & 3,59 & 0,69 \\
\hline 11 & $\begin{array}{l}\text { Propicia a compreensão dos impactos } \\
\text { sociais, resultantes da produção, gestão } \\
\text { e incorporação de novas tecnologias no } \\
\text { campo da Gestão da Qualidade }\end{array}$ & 3,56 & 0,85 \\
\hline 12 & $\begin{array}{l}\text { Propicia a compreensão dos impactos } \\
\text { econômicos, resultantes da produção, } \\
\text { gestão e incorporação de novas } \\
\text { tecnologias no campo da Gestão da } \\
\text { Qualidade }\end{array}$ & 3,59 & 0,84 \\
\hline 13 & $\begin{array}{l}\text { Propicia a compreensão dos impactos } \\
\text { ambientais, resultantes da produção, } \\
\text { gestão e incorporação de novas } \\
\text { tecnologias no campo da Gestão da } \\
\text { Qualidade }\end{array}$ & 3,85 & 0,77 \\
\hline 14 & $\begin{array}{l}\text { Propicia a avaliação dos impactos } \\
\text { sociais, resultantes da produção, gestão } \\
\text { e incorporação de novas tecnologias no } \\
\text { campo da Gestão da Qualidade }\end{array}$ & 3,63 & 0,74 \\
\hline 15 & $\begin{array}{c}\text { Propicia a avaliação dos impactos } \\
\text { econômicos, resultantes da produção, } \\
\text { gestão e incorporação de novas } \\
\text { tecnologias no campo da Gestão da } \\
\text { Qualidade }\end{array}$ & 3,52 & 0,98 \\
\hline 16 & $\begin{array}{l}\text { Propicia a avaliação dos impactos } \\
\text { ambientais, resultantes da produção, } \\
\text { gestão e incorporação de novas } \\
\text { tecnologias no campo da Gestão da } \\
\text { Qualidade }\end{array}$ & 3,63 & 0,88 \\
\hline 17 & $\begin{array}{c}\text { Promove a capacidade de continuar } \\
\text { aprendendo }\end{array}$ & 4,04 & 0,85 \\
\hline 18 & $\begin{array}{l}\text { Promove a capacidade de acompanhar } \\
\text { as mudanças no campo de trabalho da } \\
\text { Gestão da Qualidade }\end{array}$ & 3,63 & 0,88 \\
\hline
\end{tabular}




\begin{tabular}{c|c|c|c}
\hline \multicolumn{1}{l|}{ (continuaça) } & 1,15 \\
\hline $\mathbf{1 9}$ & $\begin{array}{c}\text { Incentiva o prosseguimento de estudos em } \\
\text { cursos de Pós-Graduação }\end{array}$ & 3,56 & 0,98 \\
\hline $\mathbf{2 0}$ & $\begin{array}{c}\text { Propicia flexibilidade para realização do } \\
\text { curso }\end{array}$ & 3,26 & 0,89 \\
\hline $\mathbf{2 1}$ & $\begin{array}{c}\text { Desenvolve a interdisciplinaridade na } \\
\text { estrutura curricular }\end{array}$ & 3,52 & 1,15 \\
\hline $\mathbf{2 2}$ & $\begin{array}{c}\text { Propicia oportunidade para a } \\
\text { contextualização da teoria com a prática }\end{array}$ & 3,22 & 1,07 \\
\hline $\mathbf{2 4}$ & $\begin{array}{c}\text { Propicia a atualização permanente dos } \\
\text { cursos e seus currículos }\end{array}$ & 3,30 & 1,05 \\
& $\begin{array}{c}\text { Garante a identidade do perfil profissional } \\
\text { Tecno conclógica em Gestão da Qualidade }\end{array}$ & 3,48 & 0,89 \\
\hline \multicolumn{4}{c}{3,55} \\
\hline
\end{tabular}

Fonte: Dados da pesquisa.

Tendo por base os dados apresentados na Tabela 2, verificou-se que algumas competências têm sido melhor desenvolvidas pelo curso, conforme o alto nível de satisfação dos discentes em relação à real contribuição do curso no desenvolvimento das mesmas, o que foi identificado a partir da média e do desvio padrão, conforme detalhes a seguir.

A primeira questão que apresentou maior nível de satisfação foi a de número 17, referente à capacidade de continuar aprendendo. Essa questão apresentou a maior média $(4,04)$ e baixo desvio padrão $(0,85)$, conforme Tabela 2 . Observou-se que os respondentes consideraram que o curso de Graduação Tecnológica em Gestão da Qualidade tem se preocupado em desenvolver essa competência nos discentes. Essa competência refere-se ao saber aprender, proposta por Fleury e Fleury (2004).

Kuenzer (2015) ressalta que o aumento nos índices educacionais possibilita a redução da dependência do capitalismo em relação ao trabalho qualificado, ficando, muitas vezes, os trabalhadores sujeitos à instabilidade e precarização do trabalho. Salienta-se, ainda, que a educação continuada, em muitos casos, pode estar pautada, principalmente, na certificação, em vez de uma educação de qualidade e emancipatória.

De acordo com a proposição acerca das competências profissionais feitas por Dias (2010), ao enfatizar que uma pessoa competente é aquela capaz de usar o que sabe, aquela que em várias situações ativa seus conhecimentos, capacidades e estratégias e, tendo em vista foi apontado pelos respondentes, a capacidade de continuar aprendendo é muito importante nos profissionais no mundo contemporâneo para ativar os conhecimentos em situações diversas. É necessário que se capacite continuamente, para ter conhecimentos 
Acreditase que compreender os impactos ambientais está dentro das competências requeridas dos profissionais no âmbito da lógica econômica

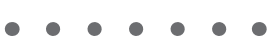

e experiências sobre inúmeras situações e conseguir ativá-los quando precisar. Contudo, Kuenzer (2015) enfatiza que a posse da teoria é importante para a efetivação da ação, mas não garante que haja ações dos sujeitos em prol de transformar a realidade, ou seja, a teoria permite transformar, mas não garante que haja ação do sujeito visando transformar.

A segunda competência que o curso tem conseguido desenvolver no corpo discente refere-se ao desenvolvimento da capacidade nos alunos de compreender as causas que justificam a implantação do processo da Qualidade (questão 3, Tabela 2). Tal competência se refere ao saber agir, proposta por Fleury e Fleury (2004). Conforme a Tabela 2, essa competência apresentou média 3,89, segundo valor mais aproximado de 5, e apresentou desvio padrão 0,89, o qual também pode ser considerado baixo.

Segundo Hypolito (2010), a escola deve ter eficiência em desenvolver a capacidade de articular teoria e prática - saber agir - sem criticismos políticos, contribuindo na formação de pessoas com um currículo necessário à reestruturação do capitalismo diante a globalização.

No que tange à terceira competência que apresentou maior tendência para satisfação, constatou-se que os discentes se sentem capazes de compreender os impactos ambientais, resultantes da produção, gestão e incorporação de novas tecnologias no campo da Gestão da Qualidade (questão 13, Tabela 2), a qual está relacionada ao saber assumir responsabilidades (FLEURY; FLEURY, 2004). Conforme apresentado na Tabela 2, a média identificada foi de 3,85 e o desvio padrão foi 0,77. Observe-se que foi uma das maiores médias apresentadas na Tabela 2, com um desvio padrão que também pode ser considerado baixo. Acredita-se que compreender os impactos ambientais está dentro das competências requeridas dos profissionais no âmbito da lógica econômica, pois as empresas estão sujeitas a fontes esgotáveis e limitadas de recursos.

Por outro lado, ainda tendo por base os resultados apresentados na Tabela 2, percebe-se que o curso em análise não está sendo tão efetivo em desenvolver algumas competências profissionais nos alunos, tendo em vista o nível de insatisfação dos discentes pesquisados em relação a algumas competências que deveriam ser desenvolvidas, identificado pela média e desvio padrão.

Assim, verificou-se que o menor nível de satisfação dos discentes foi referente à capacidade de aplicar os conhecimentos adquiridos no curso (questão 22, Tabela 2). Com base nas respostas dos discentes para essa competência constatou-se a menor média $(3,22)$, no entanto, o desvio padrão foi de certa forma alto $(1,15)$ (Tabela 2). De acordo com a percepção dos discentes, o curso pode não estar sendo tão efetivo ao contextualizar a teoria com a prática, competência referente ao saber aprender e saber agir (FLEURY; 
FLEURY, 2004). Observa-se que mesmo apresentando a menor média, pode-se dizer que os discentes não estão tão insatisfeitos assim, uma vez que o desvio padrão foi alto.

De acordo com os dados desta pesquisa, constatou-se uma tendência para insatisfação em relação à flexibilidade curricular (questão 20, Tabela 2), por ter apresentado baixa média $(3,26)$ e desvio padrão $(0,98)$. A flexibilidade curricular pode estar relacionada à capacidade de o indivíduo assumir responsabilidades (FLEURY; FLEURY, 2004), pois essa flexibilidade poderia ser uma forma de possibilitar ao aluno alinhar suas demandas profissionais e pessoais com aquelas que o curso pode desenvolver.

As deficiências do curso em estudo em desenvolver a competência de flexibilidade curricular podem se justificar pela estrutura da educação moldada pelo modo de produção, em que as competências a serem desenvolvidas nos alunos são muito bem articuladas com o desejo de manter a ordem econômica e social (HYPOLITO, 2010).

Ainda com base na Tabela 2, observa-se baixo nível de satisfação dos respondentes em relação à atualização permanente do curso e de seus currículos (questão 23), tendo em vista a média $(3,30)$ identificada. Contudo, verificou-se que o desvio padrão foi de certa forma alto $(1,07)$, podendo dizer que, apesar de parecerem insatisfeitos, houve tendência para satisfação dos discentes em relação a esse quesito. Ressalta-se que esse quesito se refere ao saber aprender, proposto por Fleury e Fleury (2004).

Diante desses resultados, percebe-se que o curso e seus currículos têm sido atualizados permanentemente. Conforme salienta Ramos (2002), a educação profissional deve atualizar os cursos continuamente, de acordo com as novas demandas organizacionais, para ser capaz de formar pessoas competentes, com habilidades alinhadas com as demandas do mercado de trabaIho. É a partir das necessidades do capitalismo que a educação é estruturada (KUENZER; GRABOWSK, 2016).

\subsection{Níveis desejáveis (ideais) do curso no desenvolvimento de competências profissionais nos discentes}

Na Tabela 3, apresentam-se os níveis desejáveis de contribuição do curso de Graduação Tecnológica em Gestão da Qualidade da IES, pesquisados no desenvolvimento de competências profissionais nos discentes, tendo por base a média e o desvio padrão.

\section{A flexibilidade curricular pode estar relacionada à capacidade de o indivíduo assumir responsabilidades}


Tabela 3 - Nível de satisfação dos discentes em relação à contribuição ideal/desejável do curso no desenvolvimento de suas competências profissionais

\begin{tabular}{|c|c|c|c|}
\hline N. & Questão & Média & $\begin{array}{l}\text { Desvio } \\
\text { Padrão } \\
\end{array}$ \\
\hline 1 & $\begin{array}{c}\text { Incentiva o desenvolvimento da capacidade } \\
\text { empreendedora nos alunos no campo da } \\
\text { Gestão da Qualidade }\end{array}$ & 4,41 & 0,75 \\
\hline 2 & $\begin{array}{c}\text { Incentiva a compreensão dos processos de } \\
\text { aferição da Qualidade }\end{array}$ & 4,48 & 0,75 \\
\hline 3 & $\begin{array}{l}\text { Promove a compreensão das causas que } \\
\text { justificam a implantação do processo da } \\
\text { Qualidade }\end{array}$ & 4,67 & 0,68 \\
\hline 4 & $\begin{array}{c}\text { Promove a compreensão dos efeitos } \\
\text { decorrentes da implantação do processo da } \\
\text { Qualidade }\end{array}$ & 4,48 & 0,85 \\
\hline 5 & $\begin{array}{l}\text { Incentiva a produção científico-tecnológica } \\
\text { e suas respectivas aplicações no campo da } \\
\text { Gestão da Qualidade }\end{array}$ & 4,48 & 0,75 \\
\hline 6 & $\begin{array}{l}\text { Incentiva a inovação científico-tecnológica, } \\
\text { e suas respectivas aplicações no campo da } \\
\text { Gestão da Qualidade }\end{array}$ & 4,30 & 0,78 \\
\hline 7 & $\begin{array}{c}\text { Desenvolve competências profissionais } \\
\text { tecnológicas gerais para a gestão de processos } \\
\text { na área da Qualidade } \\
\end{array}$ & 4,56 & 0,80 \\
\hline 8 & $\begin{array}{c}\text { Desenvolve competências profissionais } \\
\text { tecnológicas gerais para a produção de bens } \\
\text { e serviços no campo da Qualidade }\end{array}$ & 4,56 & 0,70 \\
\hline 9 & $\begin{array}{c}\text { Desenvolve competências profissionais } \\
\text { tecnológicas específicas para a gestão de } \\
\text { processos na área da Qualidade }\end{array}$ & 4,44 & 0,80 \\
\hline 10 & $\begin{array}{l}\text { Desenvolve competências profissionais } \\
\text { tecnológicas específicas para a produção de } \\
\text { bens e serviços no campo da Qualidade }\end{array}$ & 4,33 & 0,78 \\
\hline 11 & $\begin{array}{c}\text { Propicia a compreensão dos impactos } \\
\text { sociais, resultantes da produção, gestão e } \\
\text { incorporação de novas tecnologias no campo } \\
\text { da Gestão da Qualidade }\end{array}$ & 4,30 & 0,82 \\
\hline 12 & $\begin{array}{l}\text { Propicia a compreensão dos impactos } \\
\text { econômicos, resultantes da produção, gestão } \\
\text { e incorporação de novas tecnologias no } \\
\text { campo da Gestão da Qualidade }\end{array}$ & 4,41 & 0,84 \\
\hline
\end{tabular}




\begin{tabular}{|c|c|c|c|}
\hline 13 & \begin{tabular}{|c|} 
Propicia a compreensão dos impactos \\
ambientais, resultantes da produção, gestão e \\
incorporação de novas tecnologias no campo \\
da Gestão da Qualidade \\
\end{tabular} & 4,52 & 0,70 \\
\hline 14 & \begin{tabular}{|c|} 
Propicia a avaliação dos impactos \\
sociais, resultantes da produção, gestão e \\
incorporação de novas tecnologias no campo \\
da Gestão da Qualidade
\end{tabular} & 4,41 & 0,80 \\
\hline 15 & \begin{tabular}{|c|} 
Propicia a avaliação dos impactos \\
econômicos, resultantes da produção, gestão \\
e incorporação de novas tecnologias no \\
campo da Gestão da Qualidade
\end{tabular} & 4,48 & 0,75 \\
\hline 16 & \begin{tabular}{|c|} 
Propicia a avaliação dos impactos \\
ambientais, resultantes da produção, gestão e \\
incorporação de novas tecnologias no campo \\
da Gestão da Qualidade \\
\end{tabular} & 4,48 & 0,85 \\
\hline 17 & $\begin{array}{l}\text { Promove a capacidade de continuar } \\
\text { aprendendo } \\
\end{array}$ & 4,67 & 0,68 \\
\hline 18 & $\begin{array}{c}\text { Promove a capacidade de acompanhar as } \\
\text { mudanças no campo de trabalho da Gestão } \\
\text { da Qualidade }\end{array}$ & 4,44 & 0,89 \\
\hline 19 & $\begin{array}{c}\text { Incentiva o prosseguimento de estudos em } \\
\text { cursos de Pós-Graduação }\end{array}$ & 4,63 & 0,79 \\
\hline 20 & $\begin{array}{l}\text { Propicia flexibilidade para realização do } \\
\text { curso }\end{array}$ & 4,52 & 0,75 \\
\hline 21 & $\begin{array}{c}\text { Desenvolve a interdisciplinaridade na } \\
\text { estrutura curricular }\end{array}$ & 4,52 & 0,80 \\
\hline 22 & $\begin{array}{c}\text { Propicia oportunidade para a } \\
\text { contextualização da teoria com a prática }\end{array}$ & 4,52 & 1,01 \\
\hline 23 & \begin{tabular}{|c|} 
Propicia a atualização permanente dos cursos \\
e seus currículos
\end{tabular} & 4,52 & 0,94 \\
\hline 24 & $\begin{array}{l}\text { Garante a identidade do perfil profissional } \\
\text { para o concluinte do curso de Graduação } \\
\text { Tecnológica em Gestão da Qualidade }\end{array}$ & 4,63 & 0,79 \\
\hline & & 4,49 & 0,79 \\
\hline
\end{tabular}

Fonte: Dados da pesquisa.

Ao analisar a Tabela 3, verificou-se que a competência considerada mais desejável/ideal pelos discentes foi a de compreender as causas que justificam a implantação do processo da qualidade (questão 3) e que está relacionada ao saber agir (FLEURY; FLEURY, 2004). Essa competência apresentou média 4,67 e desvio padrão 0,68. Verifica-se, a partir deste achado e conforme foi apresentado na Tabela 2, que o curso tem sido efetivo em desenvolver essa 
competência nos discentes. Pode-se dizer, a partir desta constatação, que o curso desenvolve competências consideradas relevantes pelos discentes no profissional da área de Gestão da Qualidade.

Diante desses dados, fica explícito que os respondentes percebem a necessidade de integração entre teoria e prática e, ainda, que a bagagem teórica não garante que haverá uma ação do sujeito para transformar e vice-versa. Dessa forma, essas diferentes capacidades precisam estar articuladas para desencadear ação dos sujeitos (KUENZER, 2015).

Com a mesma média $(4,67)$ e mesmo desvio padrão $(0,68)$, a capacidade de continuar aprendendo (questão 17) foi apontada pelos respondentes como outra competência considerada ideal, a qual se refere ao saber aprender, proposto por Fleury e Fleury (2004).

De acordo com os dados apresentados na Tabela 2 e na Tabela 3, a capacidade de continuar aprendendo foi uma das competências profissionais considerada mais desejável pelos discentes (competências ideais), além de ter sido uma das mais desenvolvidas durante o curso (competências reais).

Esse alinhamento entre as competências reais e ideais apontadas pelos pesquisados pode se justificar pela proposição apresentada por Kuenzer e Grabowsk (2016): os projetos pedagógicos são pautados nas demandas das forças produtivas, no modelo de produção dominante. Considerando que a maioria dos pesquisados já possui experiência profissional, eles percebem as competências mais demandadas pelo mercado de trabalho.

Em seguida, com a mesma média $(4,63)$ e o mesmo desvio padrão $(0,79)$, outras duas competências foram consideradas ideais pelos respondentes. Elas estavam relacionadas à qualificação continuada após a graduação (questão 19), referente ao saber aprender (FLEURY; FLEURY, 2004) e à garantia da identidade do perfil profissional para o discente concluinte (questão 24), que está relacionada à capacidade de assumir responsabilidades tendo por base a proposta de Fleury e Fleury (2004).

Tanto a formação continuada quanto a garantia da identidade do perfil profissional são frutos das exigências da atual dinâmica do trabalho, que demanda competências dos trabalhadores bastante restritivas, de forma a perpetuar o desenvolvimento do capitalismo no mundo. E mais, essa preocupação dos estudantes quanto à educação continuada e ao perfil profissional na área de formação pode expressar o seu medo, tendo em vista a precarização social e do trabalho à qual estão sujeitos (HIRATA, 2016). Pode ainda, apontar o monitoramento da identidade do professor e do aluno por parte do Estado, de forma a perpetuar a identidade de outros sujeitos na sociedade (HYPOLITO, 2010). 
Assim, as competências que os respondentes acreditam que devem ser desenvolvidas pelos cursos de Graduação Tecnológica em Gestão da Qualidade estão relacionadas à capacidade do formando de entender o que leva a implantar o processo da qualidade e saber aprender continuamente. Essa última competência corrobora a proposição feita por Bitencourt (2002) e Paiva et al. (2011), ao afirmarem que as organizações, atualmente, exigem novas competências dos profissionais de todas as áreas, sendo a qualificação continuada uma das competências mais requeridas, o que também foi ressaltado pelos respondentes como ideal nos egressos do curso de Graduação Tecnológica em Gestão da Qualidade.

Observam-se, a partir dos dados apresentados, altos níveis desejáveis de contribuição do curso de Graduação Tecnológica em Gestão da Qualidade no desenvolvimento de competências profissionais nos discentes, levando em conta a média e o desvio padrão.

Ainda tendo por base as diretrizes curriculares e as competências apresentadas por Fleury e Fleury (2004), verificou-se que algumas competências não foram consideradas tão desejáveis pelos respondentes para os alunos da Graduação Tecnológica em Gestão da Qualidade, se forem avaliadas a média e desvio padrão.

A competência julgada menos desejável nos discentes de Gestão da Qualidade está relacionada à capacidade de avaliar os impactos sociais resultantes da produção, gestão e incorporação de novas tecnologias no campo da Gestão da Qualidade (questão 11), referente ao saber assumir responsabilidades (FLEURY; FLEURY, 2004). Essa competência apresentou uma baixa média $(4,30)$ e baixo desvio padrão $(0,82)$, conforme apresentado na Tabela 3.

Nesse sentido, pode-se dizer que os discentes julgam necessário saber agir, no entanto, acreditam não ser tão necessário avaliar os impactos sociais das ações dos profissionais no âmbito da Gestão da Qualidade. Conforme salienta Zarifian (2001), competência profissional consiste na capacidade dos indivíduos de superarem expectativas, de se sobressaírem em ambientes de mudanças constantes, serem responsáveis pelo próprio desempenho e reconhecidos por terceiros. Dessa forma, um profissional competente deve ser capaz de avaliar os impactos de suas ações, entretanto, essa competência não foi considerada tão importante pelos respondentes.

Essa pouca valorização dada pelos estudantes no que tange à capacidade de avaliar os impactos sociais resultantes da produção, gestão e incorporação de novas tecnologias no campo da Gestão da Qualidade pode caracterizar um olhar restritivo desses alunos, pois parece não existir uma consciência política da ciência, da tecnologia, das técnicas e dos instrumentos, dessa forma, não consideram de grande importância avaliar as influências 
da sua atuação nos âmbitos políticos, econômicos, sociais e culturais (FERRETTI, 2014).

Um olhar restritivo no que se refere aos impactos sociais do trabalho retrata falta de consciência do impacto das empresas em vários âmbitos
Além disso, um olhar restritivo no que se refere aos impactos sociais do trabalho retrata falta de consciência do impacto das empresas em vários âmbitos da vida do trabalhador e de suas famílias, como: desigualdade de sexos, entre classes sociais e raças e outras disparidades. Dessa forma, a configuração do trabalho acarreta tanto a precarização social quanto a do trabalho em si, perpetuando o desenvolvimento capitalista no mundo (HIRATA, 2016).

Outra competência que apresentou baixo índice de satisfação, considerada menos desejável nos profissionais que cursam a Graduação Tecnológica em Gestão da Qualidade, foi referente à aplicação de inovação científico-tecnológica no campo da Gestão da Qualidade (questão 6), relacionada ao saber agir (FLEURY; FLEURY, 2004). Para essa competência, identificou-se média 4,30 e desvio padrão de 0,78 (Tabela 3). A percepção dos discentes referente a essa competência vai de encontro às exigências organizacionais feitas atualmente aos profissionais, pois a capacidade de lidar com as inovações tecnológicas tem sido uma das competências mais demandadas no mercado de trabalho (BITENCOURT, 2002; KUENZER, 2015; PAIVA et al., 2011; RAMOS, 2002).

E ainda, outra competência que apresentou níveis de insatisfação, tendo em vista a média identificada (4,33, Tabela 3$)$ e o desvio padrão (0,78, Tabela 3), foram as específicas para a produção de bens e serviços no campo da Qualidade (questão 10), relacionadas ao saber agir (FLEURY; FLEURY, 2004).

Observa-se que os respondentes não consideram esses dois saberes específicos, capacidade de lidar com as inovações tecnológicas e as capacidades específicas para a produção de bens e serviços no campo da Qualidade, tão importantes no profissional da área. Essa percepção vai ao encontro da percepção de Kuenzer (2015): de que sob a dinâmica capitalista, os profissionais não precisam ter saberes específicos, precisam apresentar saberes gerais e flexíveis.

Pode-se dizer, diante dos dados desta pesquisa, que as competências consideradas menos desejáveis nos profissionais formados em Gestão da Qualidade, não tão ideais nos alunos, estavam relacionadas a: administração dos impactos ambientais consequentes da incorporação de novas tecnologias, aplicação de inovação científico-tecnológica e habilidade de produzir bens e serviços. 


\section{Considerações finais}

O objetivo deste estudo consistiu em analisar as contribuições do curso de Graduação Tecnológica em Gestão da Qualidade na formação de competências profissionais de discentes, na percepção dos próprios sujeitos.

Na análise dos dados, observou-se que as competências reais tiveram médias com tendência central (entre 3,26 e 4,04) e média geral de 3,68. Constatou-se que o curso tem sido mais efetivo no desenvolvimento de algumas competências, a saber: capacidade de continuar aprendendo, de compreender as causas que justificam a implantação do processo da qualidade e compreensão dos impactos ambientais, resultantes da produção, gestão e incorporação de novas tecnologias no campo da Qualidade. Com base no modelo proposto por Fleury e Fleury (2004), essas competências se referiam às seguintes habilidades: trabalhar conhecimentos e experiências, repensar modelos mentais, saber desenvolver-se e comprometer-se com os objetivos da organização (saber aprender); saber o que e o porquê fazer, julgar, escoIher e decidir (saber agir); ser responsável, assumir os riscos e as consequências de suas ações; além de ser reconhecido (assumir responsabilidades).

Em relação à contribuição ideal/desejável do curso no desenvolvimento de competências profissionais nos discentes, identificaram-se médias bem-elevadas (entre 4,30 e 4,67) e média geral 4,57, o que demonstra que todas as competências prescritas na CNE/CP n. 3 devem ser desenvolvidas pelo curso nos discentes. Na percepção dos respondentes, o curso deve desenvolver, principalmente, a capacidade de compreender as causas que justificam a implantação do processo da qualidade, de continuar aprendendo e qualificando continuamente após a graduação tecnológica. De acordo com os saberes propostos por Fleury e Fleury (2004), verificou-se que essas competências se referem ao saber agir, aprender e assumir responsabilidades.

Constatou-se que as mesmas competências que o curso está sendo capaz de desenvolver nos alunos são também consideradas pelos respondentes como as mais desejáveis nos profissionais formados pelo curso de Graduação Tecnológica em Gestão da Qualidade. Em consequência, as competências ideais e reais identificadas com base no modelo proposto por Fleury e Fleury (2004) também foram as mesmas: saber agir, aprender e assumir responsabilidades.

Diante dos resultados desta pesquisa, de modo geral, pode-se dizer que a Graduação Tecnológica em Gestão da Qualidade da IES pesquisada tem sido efetiva em desenvolver competências profissionais nos alunos. Constatou-se, ainda, que os respondentes consideraram desejável que as competências prescritas na CNE/CP n. 3 sejam efetivamente desenvolvidas nos discentes pelo curso. Verificou-se também que as competências prescritas na $\mathrm{CNE} / \mathrm{CP}$ 


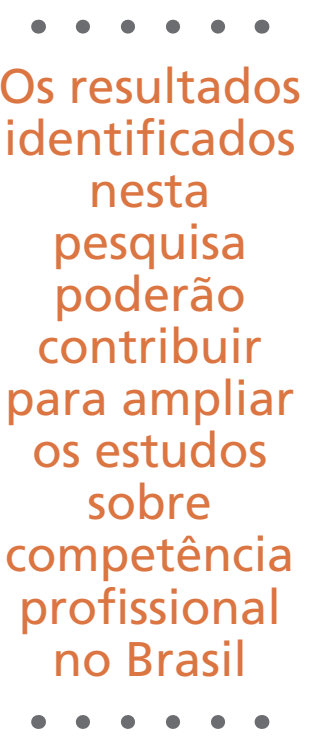

n. 3, as ideais e as reais apontadas pelos estudantes, estão alinhadas com as demandadas pelo modo de produção capitalista presente na sociedade.

Os resultados identificados nesta pesquisa poderão contribuir para ampliar os estudos sobre competência profissional no Brasil e, ainda, auxiliar na reorganização dos cursos desta e de outras IES privadas, tendo em vista desenvolver nos alunos competências profissionais voltadas para as novas demandas das organizações.

Considerando que este estudo possui limitações, sugere-se que outros sejam realizados, tomando como base a percepção de outros sujeitos, em outras IES e em outros cursos, buscando identificar suas contribuições no efetivo desenvolvimento de competências profissionais de seus discentes.

\section{Referências}

BARBOSA, M. L. O. Ensaio Bibliográfico: as profissões no Brasil e sua sociologia.

Dados, Rio de Janeiro, v. 46, n. 3, p. 593-607, 2003.

BITENCOURT, C. A gestão de competências como alternativa de formação e desenvolvimento nas organizações: uma reflexão crítica a partir da percepção de um grupo de gestores. In: ENCONTRO DA ASSOCIAÇÃO NACIONAL DE PÓSGRADUAÇÃO E PESQUISA EM ADMINISTRAÇÃO, 26., 2002, Salvador. Anais... Rio de Janeiro: ANPAD, 2002.

BITENCOURT, C.; BARBOSA, A. C. Q. A gestão de competências. In: BITENCOURT, C. (Org.). Contemporânea de pessoas. Porto Alegre: Bookman, 2004.

BRANDÃO, H. P. Competências no trabalho e nas organizações: uma análise da produção científica brasileira. In: ENCONTRO DA ASSOCIAÇÃO NACIONAL DE PÓSGRADUAÇÃO E PESQUISA EM ADMINISTRAÇÃO, 30., 2006, Salvador. Anais... Rio de Janeiro: ANPAD, 2006.

CEITIL, M. Proposta de definição do conceito de competências. In: CEITIL, M. (Org.).

Gestão e desenvolvimento de competências. Lisboa: Europress, 2010. p. 39-44.

CHEETHAM, G.; CHIVERS, G. Towards a holistic model professional of competence. Journal of European Industrial Training, v. 20, n. 5, p. 20-30, 1996.

CONSELHO NACIONAL DE EDUCAÇÃO (Brasil). Conselho Pleno. Resolução CNE/CP 3, 2002. Institui as Diretrizes Curriculares Nacionais Gerais para a organização e 0 funcionamento dos cursos superiores de tecnologia. Diário Oficial da União, Brasília, DF, p. 4, 18 dez. 2002.

DIAS, I. S. Competências em educação: conceito e significado pedagógico. Revista Semestral da Associação Brasileira de Psicologia Escolar e Educacional, São Paulo, v. 14, n. 1, p.73-78, jan./jun. 2010. Disponível em <http://www.scielo.br/pdf/ pee/v14n1/v14n1a08.pdf>. Acesso em: 20 set. 2014. 
DUTRA, J. S.; HIPÓLITO J. A. M.; SILVA. C. M. Gestão de pessoas por competências: 0 caso de uma empresa do setor de telecomunicações. Revista de Administração Contemporânea, Rio de Janeiro, v. 4, n. 1, p. 161-176, jan./abr. 2000.

FERRETTI, C. J. Desenvolvimento nacional e regional e as demandas ao campo da educação. Germinal: Marxismo e educação em debate, v. 6, n. 2, p. 54-64, dez. 2014.

FLEURY, A. C.; FLEURY, M. T. L. Estratégias empresariais e formação de competências. São Paulo: Atlas, 2001.

FLEURY, A. C.; FLEURY, M. T. L. Estratégias empresariais e formação de competências: um quebra-cabeça caleidoscópico da indústria brasileira. 3. ed. São Paulo: Atlas, 2004.

FLEURY, M. T. L.; VASCONCELLOS, L. A. A contribuição do e-learning no desenvolvimento de competências do administrador: considerando o estilo de aprendizagem do aluno de graduação. Revista Brasileira de Docência, Ensino e Pesquisa em Administração, Cristalina, v. 1, n. 1, p. 137-157, 2009.

FRAUCHES, C. (Org.). Diretrizes curriculares nacionais para os cursos de graduação. Brasília, DF: ABMES, 2008.

GIL-ESTALLO, M. et al. New competences form crisis times. International Advances in Economic Research, v. 16, p. 190-202, 2010.

GODOY, A. S. Introdução à pesquisa qualitativa e suas possibilidades. Revista de Administração de Empresa, v. 35, n. 2, p. 57-63, 1995.

HIRATA, H. Trabalho gênero e dinâmicas internacionais. Revista da ABET, v. 15, n. 1, p. 9-21, jan./jun. 2016.

HYPOLITO, A. M. Políticas curriculares, estado e regulação. Educação e Sociedade, Campinas, v. 31, n. 113, p. 1337-1354, out./dez. 2010.

KUENZER, A. Z. 0 pensamento pedagógico da região sul: pesquisando a relação entre trabalho e educação. Revista Pedagógica, Chapecó, v. 17, n. 36, n. 30-50, set./dez. 2015.

KUENZER, A. Z.; GRABOWSK, G. A produção do conhecimento no campo da educação profissional no regime de acumulação flexível. HOLOS, Natal, v. 6, n. 32, p. 22-32, 2016.

LE BOTERF, G. Desenvolvendo a competência dos profissionais. Porto Alegre: Artmed, 2003.

PAIVA, K. C. M. et al. Competências profissionais e interdisciplinaridade no Direito: percepções de discentes de uma faculdade particular mineira. Educação e Pesquisa, São Paulo, v. 37, p. 355-373, 2011.

PAIVA, K. C. M. et al. Percepções de alunos e professores do curso de Administraç̧ão a respeito da educação à distância: um estudo em uma instituição particular brasileira. Tourism \& Management Studies, Faro, v. 1, p. 354-366, 2013. Edição especial.

B. Téc. Senac, Rio de Janeiro, v. 43, n. 2, p. 102-127, maio/ago. 2017. 
PAIVA, K. C. M.; MELO, M. C. O. L. Competências, gestão de competências e profissões: perspectivas de pesquisas. Revista de Administração Contemporânea, Curitiba, v.12, n. 2, p. 339-368, abr./jun. 2008. Disponível em: <http://www.scielo.br/pdf/rac/ v12n2/a04v12n2.pdf>. Acesso em: 29 set. 2014.

RAMOS, M. N. A pedagogia das competências: autonomia ou adaptação? 2. ed. São Paulo: Cortez, 2002.

SCHAEPER, H. Development of competencies and teaching-learning arrangements in higher education: findings from Germany. Studies in Higher Education, London, v. 34, n. 6, p. 677-697, 2009.

SEVERINO, A. J. Metodologia do trabalho científico. 23. ed. São Paulo: Cortez, 2007.

SILVA, A. B. 0 contexto social da aprendizagem de gerentes. Revista de Administração Mackenzie, São Paulo, v. 9, p. 26-52, 2008.

STEFFEN, I. Modelos de competência profissional. [S.I.: s.n.], 1999. p.1-14.

VERGARA, S. C. Projetos e relatórios de pesquisa em administração. São Paulo: Atlas, 2009.

ZABALA, A.; ARNAU, L. Como aprender e ensinar competências. Porto Alegre: Artmed, 2010.

ZARIFIAN, P. Objetivo competência. São Paulo: Atlas, 2001. 